\title{
S. mutans biofilm model to evaluate antimicrobial substances and enamel demineralization
}

\section{Renzo Alberto Ccahuana- Vásquez ${ }^{(a)}$ \\ Jaime Aparecido Cury ${ }^{(b)}$}

(a) $\mathrm{PhD}$ in Cariology, (b) PhD, Professor of Biochemistry and Cariology - Piracicaba Dental School, University of Campinas (UNICAMP), Piracicaba, São Paulo, Brazil.

\section{Corresponding author:}

Jaime Aparecido Cury

Faculdade de Odontologia de Piracicaba, UNICAMP

CP 52

Piracicaba - SP - Brazil

CEP: 13414-903

E-mail: jcury@fop.unicamp.bror jaimcury@dglnet.com.br

Received for publication on May 10, 2010 Accepted for publication on May 24, 2010

\begin{abstract}
The aim of this study was to validate a model of $S$. mutans biofilm formation, which simulated 'feast-famine' episodes of exposure to sucrose that occur in the oral cavity, showed dose-response susceptibility to antimicrobials and allowed the evaluation of substances with anticaries potential. S. mutans UA159 biofilms were grown for 5 days on bovine enamel slabs at $37^{\circ} \mathrm{C}, 10 \% \mathrm{CO}_{2}$. To validate the model, the biofilms were treated $2 \mathrm{x}$ /day with chlorhexidine digluconate $(\mathrm{CHX})$ at $0.012,0.024$ and $0.12 \%$ (concentration with recognized anti-plaque effect) and $0.05 \% \mathrm{NaF}$ (concentration with recognized anti-caries effect). CHX showed dose-response effect decreasing biomass, bacterial viability and enamel demineralization $(\mathrm{p}<0.05)$. Whereas, $0.05 \% \mathrm{NaF}$ did not show antimicrobial effect but had similar effect to that of $0.12 \% \mathrm{CHX}$ decreasing enamel demineralization $(\mathrm{p}<0.05)$. The model developed has potential to evaluate the effect of substances on biofilm growth and on enamel demineralization.
\end{abstract}

Descriptors: Streptococcus mutans; Biofilms; Chlorhexidine; Sucrose; Dental caries.

\section{Introduction}

Dental biofilm is an organized microbiologic community enclosed in a matrix of extracellular material and attached to dental surfaces. ${ }^{1}$ Under some conditions, such as high carbohydrate consumption, the presence of a high amount of sugars can change the biochemical and microbiological composition of biofilm, leading to an increase in the proportion of pathogenic species and transforming healthy biofilm into cariogenic biofilm. Moreover, depending on the frequency this can lead to the formation and development of dental caries disease. ${ }^{2}$

In the oral cavity, the microorganisms in dental biofilm are exposed to large amounts of sugar during a short period of time and some microorganisms have the capacity to use these carbohydrates to produce acid, synthesize extracellular polysaccharides and store energy. After this rapid exposure to sugar, dental biofilm undergoes long periods of sugar starvation. These physiological conditions of bacterial growth are known as 'feast or famine' episodes ${ }^{3}$ and can cause microbiological selection strategies that increase the proportion of acid-tolerant species such as $S$. mutans in biofilm. ${ }^{4,5}$

S. mutans are considered the most cariogenic microorganisms in 
dental biofilm due to their capacity to use dietary carbohydrates such as sucrose, to synthesize extracellular polysaccharides (EPS) and because of their acidogenic and aciduric properties. ${ }^{4}$ EPS are important virulence factors of $S$. mutans because they promote bacterial adherence to the tooth surface, ${ }^{6,7}$ contribute to the structural integrity of dental biofilms ${ }^{8,9}$ change the porosity of the biofilm ${ }^{10}$ and consequently increase enamel demineralization. ${ }^{11}$ Therefore, S. mutans biofilms have been used to evaluate their cariogenic properties due to difficulties of developing in vivo studies in controlled cariogenic situations. ${ }^{12}$

However, in most $S$. mutans biofilm models, the biofilm is grown under constant exposure to carbohydrates, which maintains the biofilm under constant acid stress, and does not simulate the "feast and famine" episodes of sugar exposure and $\mathrm{pH}-\mathrm{cy}-$ cling that occur in the oral cavity. ${ }^{13,14,15}$ In addition, these protocols do not use dental substrates to evaluate the effect of antimicrobial substances on dental demineralization caused by the attached biofilm. Furthermore, an important requirement of biofilm models is that they should show a dose-response effect against antimicrobial substances. With regard to oral biofilm models, chlorhexidine has been used as the 'gold standard' because it is considered the most efficient topical substance to reduce dental plaque, a type of biofilm. ${ }^{16}$ Moreover, it is recognized that although fluoride is the most important anticaries substance, ${ }^{17}$ its antibacterial effect is limited ${ }^{18}$ and the model should simulate the main mechanism of action of fluoride on dental caries.

Therefore, the aim of this study was to validate a $S$. mutans biofilm model that simulates exposure to sucrose that occurs in the oral environment, and allows the evaluation of the effect of antimicrobial substances on biofilm formation and on enamel demineralization.

\section{Material and Methods Experimental design}

This $S$. mutans biofilm model was a modified version detailed by Koo et al., ${ }^{13}$ (2003) with the main modifications being the use of dental substrate and the simulation of 'feast or famine' episodes of exposure to sucrose. Therefore, S. mutans UA159 biofilms were formed on saliva-coated bovine enamel slabs suspended vertically in ultrafiltered $(10 \mathrm{kDa}$ molecular weight cut-off membrane; Amicon) tryptone-yeast extract broth (UTYEB) at $37^{\circ} \mathrm{C}, 10 \%$ $\mathrm{CO}_{2}$ for 5 days $^{13}$ and exposed $1 \mathrm{~min}, 8 \mathrm{x} /$ day to $10 \%$ sucrose. After $48 \mathrm{~h}$, the growth of some biofilms $(n=4)$ was stopped (baseline) and the others were grown for another 3 days and treated $2 \mathrm{x} /$ day for 1 min with one of the following solutions: 1) $0.9 \%$ $\mathrm{NaCl}$ (Control, $\mathrm{n}=4$ ), 2) $0.012 \%$ chlorhexidine digluconate (CHX, $\mathrm{n}=4), 3)$ 0.024\% CHX $(\mathrm{n}=4)$, 4) $0.12 \% \mathrm{CHX}(\mathrm{n}=4)$ and 5) $0.05 \% \mathrm{NaF}(\mathrm{n}=4)$. The biomass, viable bacteria and biochemical composition of all biofilm samples were determined. Besides, the mineral loss of enamel slabs was assessed. The $\mathrm{pH}$ of the culture media was determined daily as an indicator of biofilm acidogenicity. For statistical evaluation each biofilm was considered an experimental block.

\section{Enamel block preparation}

Bovine incisor teeth, from which the roots were removed, were stored in $2 \%$ formol solution for a period of at least 30 days. ${ }^{19}$ The dental crown was fixed in an acrylic base, and with the aid of two parallel disks spaced $4 \mathrm{~mm}$ apart, a longitudinal slice was obtained from the central part of the dental specimen. Using two parallel disks spaced $7 \mathrm{~mm}$ apart, this slice was transversally cut. The dentin of this $7 \times 4 \mathrm{~mm}$ dental slab was completely worn in grinder machine (Phoenix Beta, Buehler, Lake Bluf, IL, USA) using 400-grit aluminum oxide abrasive paper. Enamel surfaces were polished, flattened and baseline enamel surface hardness was determined on the outer enamel surface by making 3 indentations, spaced $100 \mu \mathrm{m}$ from each other, using a Knoop indenter with a $25 \mathrm{~g}$ load for $5 \mathrm{~s}$ and a microhardness tester coupled to FM-ARS 900 software (Future-Tech FM, Kawasaki, Japan). Slabs presenting hardness of $331.69 \pm 13.81 \mathrm{~kg} / \mathrm{mm}^{2}$ were randomly divided into six groups $(n=4)$.

Each slab was individually placed in $1 \mathrm{ml}$ of a solution containing $0.06 \mathrm{mM} \mathrm{P}_{\mathrm{i}}$ and $0.08 \mathrm{mM} \mathrm{Ca}^{++}$ and sterilized by autoclaving (a previously standardized condition, data not published). The sterilized 
slabs were anchored vertically on metal devices and suspended in a 24 -well culture plate.

\section{Biofilm growth}

UTYEB was used as culture media ${ }^{13}$ and depending on the experimental phase, the media contained $1 \%$ glucose, $1 \%$ sucrose or $0.1 \mathrm{mM}$ glucose as described as follows. S. mutans UA159 colonies were transferred to UTYEB containing 1\% glucose and incubated at $37^{\circ} \mathrm{C}, 10 \% \mathrm{CO}_{2}$ to reactivate the microorganisms. The slabs on which human salivary pellicle was formed, were individually positioned in wells containing $2.0 \mathrm{ml}$ of the inoculum and were incubated at $37^{\circ} \mathrm{C}, 10 \% \mathrm{CO}_{2}$ to allow bacterial adhesion on the acquired pellicle. All these procedures were carried out according to Koo et al. ${ }^{13}$ (2003) but $8 \mathrm{~h}$ (previously standardized) after incubation the slabs were transferred to the fresh UTEYB containing $0.1 \mathrm{mM}$ glucose (salivary basal concentration) and incubated for an additional $16 \mathrm{~h}$ at $37^{\circ} \mathrm{C}$, $10 \% \mathrm{CO}_{2}$. The next day, the biofilms on enamel slabs were transferred to fresh UTYEB containing $0.1 \mathrm{mM}$ glucose and were exposed $8 \mathrm{x} / \mathrm{day}$ for $1 \mathrm{~min}$ to $10 \%$ sucrose (containing $1.23 \mathrm{mM} \mathrm{Ca}, 0.74 \mathrm{mM}$ $\mathrm{P}_{\mathrm{i}}$ and $0.023 \mu \mathrm{g} \mathrm{F} / \mathrm{mL}$, previously standardized) at predetermined times $(8: 00,9: 30,11: 00,12: 30$, 14:00, 15:30, 17:00 and 18:30 h). This procedure was repeated for the next 3 days. After each sucrose exposure, the biofilms on enamel slabs were washed 3 times in $0.01 \% \mathrm{NaCl}$. The $\mathrm{pH}$ of the culture media was determined every $24 \mathrm{~h}$ and the media was replaced with a fresh solution.

\section{Treatments}

The CHX solutions were prepared from 20\% chlorhexidine digluconate (Sigma, Steinheim, Germany) using sterilized distilled water. The solution of $0.05 \% \mathrm{NaF}$ was prepared and sterilized by autoclaving. The treatments were performed $2 x /$ day, after the first and the last sucrose exposure of the day. After each treatment, the biofilms on enamel slabs were washed 3 times in $0.9 \% \mathrm{NaCl}$.

\section{Biofilm collection}

After the assigned experimental time of biofilm growth, the enamel slabs containing the biofilms were washed 3 times in $0.9 \% \mathrm{NaCl}$ and individually transferred to microcentrifuge tubes containing $1 \mathrm{ml}$ of $0.9 \% \mathrm{NaCl}$. The tubes were sonicated at $7 \mathrm{~W}$ for $30 \mathrm{~s}$ (Branson, Sonifier 50, Danbury, CT USA) to detach the biofilms formed on the slabs. ${ }^{20}$ The slabs were carefully removed from the suspension and stored to determine enamel demineralization. Aliquots of the suspension were used to determine biofilm bacterial viability, biomass (dry weight and total soluble proteins) and polysaccharides.

\section{Biomass determination}

Biofilm dry weight was determined according to Koo et al. ${ }^{13}$ (2003) from $200 \mu \mathrm{l}$ of the suspension. To determine total soluble protein, ${ }^{21} 50 \mu \mathrm{l}$ of the suspension was transferred to a microcentrifuge tube, to which the same volume of $2 \mathrm{M} \mathrm{NaOH}$ was added. The tube was vortexed and placed at $100^{\circ} \mathrm{C}$ at $15 \mathrm{~min}$, centrifuged $\left(10000 \mathrm{~g}\right.$ for $\left.10 \mathrm{~min}, 4^{\circ} \mathrm{C}\right)$ and the concentration of soluble protein was determined in the supernatant (DC Protein Assay, BioRad, Hercules, Ca, USA).

\section{Bacterial viability}

An aliquot of $100 \mu \mathrm{l}$ of the suspension was diluted in $0.9 \% \mathrm{NaCl}$ in series up to $10^{-7}$ and 2 drops of $20 \mu \mathrm{l}$ of each dilution were inoculated on BHI agar (BD, Sparks, USA) to determine the number of viable microorganisms. ${ }^{22}$ The plates were incubated for $48 \mathrm{~h}$ at $37^{\circ} \mathrm{C}, 10 \% \mathrm{CO}_{2}$ (IG 150 , Jouan incubator). $\mathrm{CFU}$ were counted and the results were expressed as CFU/mg of biofilm dry weight. ${ }^{20}$

\section{Polysaccharide analyses}

From $100 \mu \mathrm{l}$ of the suspension, insoluble and soluble extracellular polysaccharides were extracted according to Aires et al. ${ }^{20}$ (2008) and analyzed for total carbohydrate according to Dubois et al. ${ }^{23}$ (1956). The results were normalized by biofilm dry weight.

\section{Enamel demineralization assessment}

At the end of each experimental phase, the enamel slab surface hardness $(\mathrm{SH})$ was again measured. One row of three adjacent indentations spaced at $100 \mu \mathrm{m}$ was made $100 \mu \mathrm{m}$ from the three baseline 
measurements. The mean values of the three baseline indentations and the three measurements after treatments were then averaged and the \% SHL was calculated as follows:

$$
\underline{\text { (baseline } \mathrm{SH}-\mathrm{SH} \text { after treatment }) \times 100}
$$$$
\text { baseline } \mathrm{SH}
$$

Surface hardness loss (SHL) was used as indicator of enamel demineralization. ${ }^{11}$

\section{Statistical analysis}

The assumptions of equality of variances and normal distribution of errors were checked for all the response variables tested and those that did not satisfy these conditions were transformed. ${ }^{24}$ The relationship between CHX concentrations and the variable evaluated was estimated by regression analysis. When significant correlation was found, the data were submitted to ANOVA followed by Tukey's test, with the exception of acidogenicity, which was analyzed by repeated measures. Original data were used with the exception of viable bacteria counts, which were transformed to $\log _{10}$. The software SPSS for Windows 15.0 (SPSS, Chicago, IL, USA) was used and the significance level was fixed at $5 \%$.

\section{Results}

A statistically significant linear effect was found between $\mathrm{CHX}$ concentration and biofilm dry weight, total soluble proteins and viable bacteria, and enamel demineralization (Table 1), showing dose-response effect for these variables. No effect on polysaccharides was found.

As regards the $\mathrm{pH}$ of the culture media (Graph 1), the groups did not differ statistically after $48 \mathrm{~h}$ of the biofilm growth $(\mathrm{p}>0.05)$. At $72 \mathrm{~h}$ of biofilm growth, the $\mathrm{pH}$ of media for the $0.12 \% \mathrm{CHX}$ treatment was similar to that of the $\mathrm{NaF} 0.05 \%$ group $(p>0.05)$ but higher than that of the other groups $(\mathrm{p}<0.05)$. At the $72 \mathrm{~h}$ and $120 \mathrm{~h}$ of biofilm growth, the $\mathrm{pH}$ of the $\mathrm{NaF} 0.05 \%$ was similar to that of the control group $(p>0.05)$ but lower than that of the other groups $(\mathrm{p}<0.001)$.

The dry weight and protein values (Graph 2) showed that the biomass of the biofilm treated with $0.12 \% \mathrm{CHX}$ had lower values than those of the control $(\mathrm{p}=0.001$ and 0.07 , respectively) and it did not differ statistically from the baseline value $(\mathrm{p}=0.11$ and 0.99 , respectively). However, the values of the biomass of biofilm treated with $0.05 \% \mathrm{NaF}$ did not

Table 1 - Correlation ( $r$ ) and significance ( $p$ ) between chlorhexidine concentration $(0-0.12 \%)$ and the response variables.

\begin{tabular}{c|c|c}
\hline Variables & $r$ & $p$ \\
\hline Dry weight & -0.808 & $<0.001$ \\
\hline Proteins & -0.767 & 0.001 \\
\hline Viable bacteria & -0.689 & 0.006 \\
\hline$\% S H L$ & -0.628 & 0.009 \\
\hline IEPS & 0.148 & 0.615 \\
\hline SEPS & 0.249 & 0.412 \\
\hline
\end{tabular}

$* \% \mathrm{SHL}=$ Percentage of surface hardness loss. IEPS = Insoluble extrapolyssacharides. SEPS = Soluble extrapolyssacharides.
Graph 1 - pH of the culture medium after 48 of biofilm growth in the absence of treatments and at each $24 \mathrm{~h}$ after beginning the treatments $(72,96$ and $120 \mathrm{~h}$ data). The statistical significance among the treatments is described in the Results section ( $n=4)$.

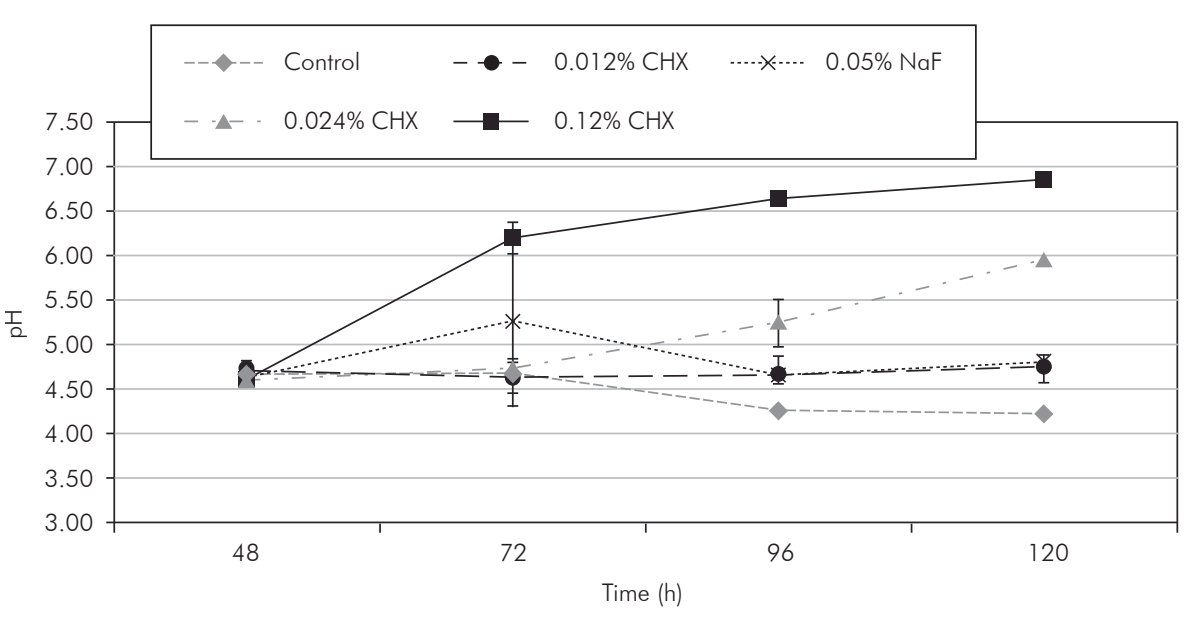


differ from those of the control $(\mathrm{p}=0.209$ and 0.758 , respectively) but were higher than the baseline values ( $\mathrm{p}=0.001$ and 0.045 , respectively) (Graph 2).

The viable bacteria count in the biofilm (Graph 3), normalized by biofilm dry weight, was significantly lower $(\mathrm{p}<0.001)$ for the treatment with $0.12 \% \mathrm{CHX}$ when compared with the baseline and the control group. However, the viable bacteria counts of biofilm treated with $0.05 \% \mathrm{NaF}$ did not differ from those of the control and the baseline val-

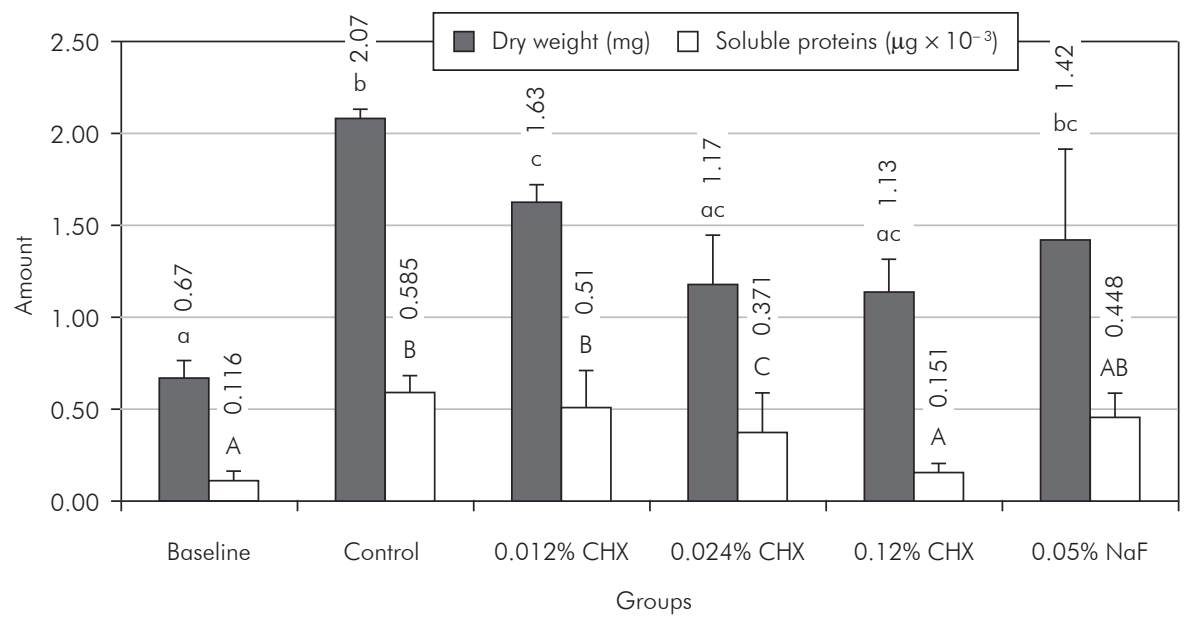

Graph 2 - Means of biofilm dry weight (mg) and amount of soluble proteins $\left(\mu \mathrm{g} \times 10^{-3}\right)$ for the baseline and according to the treatments $(n=4)$.

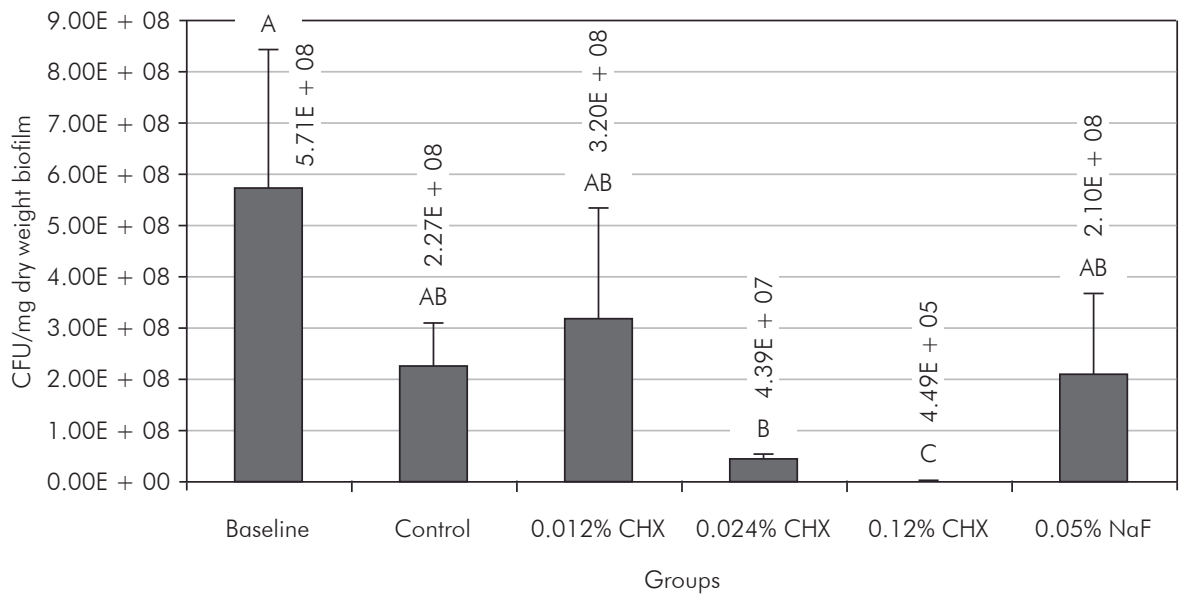

Graph 3 - Means of viable bacteria (CFU/mg dry weight) in the biofilms grown for $48 \mathrm{~h}$ in the absence of the treatments (baseline) and after 3 days of treatments described $(n=4)$. Data were transformed by $\log _{10}$.

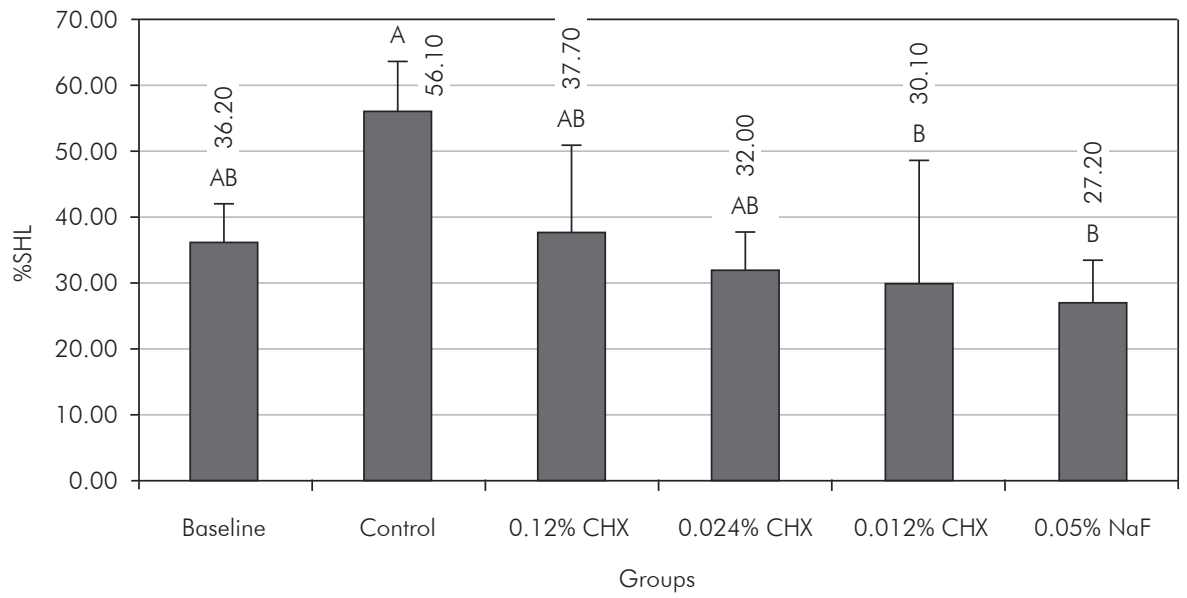

Graph 4 - Means of enamel demineralization (\%SHL) after $48 \mathrm{~h}$ of biofilm growth in the absence of the treatments (baseline) and after 3 days of the treatments described. $(n=4)$.

[Vertical bars denote standard deviations, and significant differences among the groups are indicated by different letters $(p<0.05)$.] 
ues $(\mathrm{p}=0.998$ and 0.511 , respectively).

As regards enamel demineralization (Graph 4), $0.12 \%$ CHX and $0.05 \%$ NaF significantly reduced the \%SHL when compared with the control $(\mathrm{p}=0.036$ and 0.017 , respectively), but these treatments did not differ between them $(\mathrm{p}=0.99)$.

\section{Discussion}

Biofilm models are important tools to evaluate the biochemical and microbiological composition of biofilm formed under different conditions or the changes caused on the substratum surface on which the biofilm is attached. Therefore, the conditions of biofilm formation and the substratum used must be as close as possible to those of real life.

The improved model of $S$. mutans biofilm growth was validated and dose response effect of CHX on $S$. mutans biofilm was shown for most variables (Table 1). Therefore, the model is sufficiently sensitive to show biofilm and enamel demineralization changes in the presence of antimicrobial substances. The treatment $2 \mathrm{x} /$ day with $0.12 \% \mathrm{CHX}$ showed a bactericidal effect, killing a large proportion of the viable bacteria in the biofilm (Graph 3), decreasing the biofilm capacity to produce acids (Graph 1), avoiding the increase in biofilm mass (dry weight and total proteins) (Graph 2) and consequently, the enamel demineralization process was stopped (Graph 4). This effect may be attributed to the ability of the CHX molecule to bind to the negatively charged bacterial cell surface, alter and disrupt the integrity of the cell membrane, causing bacterial death. ${ }^{25,26}$ The concentration of $0.012 \%$ CHX had a bacteriostatic effect, not interfering in the viable bacteria counts, but affecting the acid production level, which was lower than that of the control group, but it was not able to prevent enamel demineralization. At this sublethal stage, the effects of CHX are reversible; removal of excess CHX by neutralizers allows the bacterial cell to recover. ${ }^{26}$ This implies that the structural damage caused by $0.012 \% \mathrm{CHX}$ was less than that caused by $0.024 \%$ and $0.12 \%$ CHX. The results found with the use of this model are supported by a clinical trial showing that $0.12 \% \mathrm{CHX}$ is more effective in reducing $S$. mutans CFU than lower concentra- tions. $^{27}$

As opposed to CHX, fluoride did not show any effect on biofilm formation based on biomass (Graph 2) and viable bacteria counts (Graph 3). It also did not inhibit sucrose fermentation since the $\mathrm{pH}$ of the media did not differ when compared with the control (Graph 1), nevertheless, it reduced enamel demineralization (Graph 4). The findings are supported by the knowledge that at least $10 \mathrm{ppm}$ of fluoride constantly in the media is necessary to inhibit sugar fermentation. ${ }^{28}$ In this model, simulating the clinical use of mouthrinse, although the biofilm was treated with $225 \mathrm{ppm}$ of fluoride, the duration time of treatment was only $1 \mathrm{~min}$. Although $0.05 \% \mathrm{NaF}$ showed absence of antimicrobial effect, it reduced enamel demineralization, suggesting that the main effect of $\mathrm{F}$ on caries control is physicochemical. ${ }^{29,30}$

Moreover, the findings suggest that CHX did not have a direct effect on the synthesis of extracellular polysaccharides (Table 1). This result is apparently in disagreement with Koo et al. ${ }^{13}$ (2003) but it reflects the way in which the results were expressed. Koo et al. ${ }^{13}$ (2003) expressed the results in amount of polysaccharides found in the biofilm and in the present study the results were normalized by biofilm dry weight. Since the biofilm weight increased (Graph 2) but the viable bacteria decreased (Graph $3)$, the reduction in the amount of EPS should be attributed to bacterial death and not to a specific effect of CHX inhibiting the synthesis of extracellular polysaccharides.

In conclusion, the results suggest this improved $S$. mutans model can be used to test the effect of antimicrobial agents on biofilm growth and on enamel demineralization.

\section{Acknowledgments}

The manuscript was based on a thesis submitted by the first author to the Faculty of Dentistry of Piracicaba, UNICAMP, SP, Brazil, in partial fulfillment of the requirements of the Doctoral Program in Dentistry, concentration in Cariology. The study was supported by FAPESP (Proc. 2005/05143-8), CNPq (Proc. 475800/2007-9) and FUNCAMP (Conv. 4252). 


\section{References}

1. Marsh PD. Are dental disease examples of ecological catastrophes? Microbiology. 2003 Feb;149(2):279-94.

2. Takahashi N, Nyvad B. Caries ecology revisited: Microbial dynamics and the caries process. Caries Res. 2008 Oct;42(6):409-18.

3. Carlsson J. Bacterial metabolism in dental biofilms. Adv Dental Res. 1997 Apr;11(1):75-80.

4. Loesche WJ. Role of Streptococcus mutans in a human dental decay. Microbiol Rev. 1986 Dec;50(4):353-80.

5. Marsh PD. Dental as plaque biofilm and a microbial community: implications for health and disease. BMC Oral Health. 2006 Jun;6 Suppl 1:S1-S14.

6. Rölla G. Why is sucrose so cariogenic? The role of glucosyltransferases and polysaccharides. Scand J Dent Res. 1989 Apr;97(2):115-9.

7. Schilling KM, Bowen WH. Glucans synthesized in situ experimental salivary pellicle function as specific bindings sites for Streptococcus mutans. Infect Immun. 1992 Jan;60(1):28495.

8. Koo H, Xiao J, Klein MI. Extracellular Polysaccharides matrix- An often forgotten virulence factor in oral biofilm research. Int J Oral Sci. 2009 Dec;1(4):229-34.

9. Xiao J, Koo H. Structural organization and dynamics of exopolysaccharide matrix and microcolonies formation by Streptococcus mutans in biofilms. J Appl Microbiol. 2010 Jun;108(6):2103-13.

10. Dibdin GH, Shellis RP. Physical and biochemical studies of Streptococcus mutans sediments suggest new factors linking the cariogenicity of plaque with its extracellular polysaccharide content. J Dent Res. 1988 Jun;67(6):890-5.

11. Cury JA, Rebelo MA, Del Bel Cury AA, Derbyshire MT, Tabchoury CP. Biochemical composition and cariogenicity of dental plaque formed in the presence of sucrose or glucose and fructose. Caries Res. 2000 Nov-Dec;34(6):491-7.

12. Sissons $\mathrm{CH}$. Artificial dental plaque biofilm model systems. Adv Dent Res. 1997 Apr;11(1):110-26.

13. Koo H, Hayacibara MF, Schobel BD, Cury JA, Rosalen PL, Park YK et al. Inhibition of Streptococcus mutans biofilm accumulation and polysaccharide production by apigenin and tt-farnesol. J Antimicrob Chemother. 2003 Nov;52(5):7829.

14. Coenye T, Honraet K, Rigole P, Jimenez PN, Nelis HJ. In vitro inhibition of Streptococcus mutans biofilm formation on hydroxyapatite by subinhibitory concentrations of anthraquinones. Antimicrob Agents Chemother. 2007 Apr;51(4):15414.
15. Deng DM, Hoogenkamp MA, Ten Cate JM, Crielaard W. Novel metabolic activity indicator in Streptococcus mutans biofilms. J Microbiol Methods. 2009 Apr;77(1):67-71.

16. Jones CG. Chlorhexidine: Is it still the gold standard? Periodontol 2000. 1997 Oct;15(1):55-62.

17. Marinho VCC. Evidence-based effectiveness of topical fluorides. Adv Dent Res. 2008 Jul;20(1):3-7.

18. Emilson CG. Potential efficacy of chlorhexidine against mutans streptococci and human dental caries. J Dent Res. 1994 Mar;73(3):682-91.

19. White DJ. Reactivity of Fluoride Dentifrice with Artificial Caries. I. Effects on subsurface lesion: F uptake, distribution, surface, hardening and remineralization. Caries Res. 1987;21:126-40.

20. Aires CP, Del Bel Cury AA, Tenuta LMA, Klein MI, Koo H, Duarte $S$ et al. Effect of sucrose and starch on dental biofilm formation and on dentin demineralization. Caries Res. 2008 Sep;42(5):380-6.

21. Lowry OH, Rosebrough NJ, Farr AL, Randall RJ. Protein measurement with the Folin phenol reagent. J Biol Chem. 1951 Nov;193(1):265-75.

22. Herigstad B, Hamilton M, Heersink J. How to optimize the drop plate method for enumerating bacteria. J Microbiol Methods. 2001 Mar;44(2):121-9.

23. Dubois M, Gilles KA, Hamilton JK, Rebers PA, Smith F. Colorimetric method for determination of sugars and related substances. Anal Chem. 1956 Mar;28(3):350-6.

24. Box GEP, Hunter WG, Hunter JS. Statistics for experimenters. New York: Wiley, c1978. 656 p.

25. Hugo WB, Longworth AR. Some aspects of the mode of action of chlorhexidine. J Pharm Pharmacol. 1964 Oct;16:655-62.

26. Rölla G, Melsen B. On the mechanism of the plaque inhibition by chlorhexidine. J Dent Res. 1975 Jun;54 (Spec No B): B57- 62 .

27. Clark DC, Guest JL. The effectiveness of three different strengths of chlorhexidine mouthrinse. J Can Dent Assoc. 1994 Aug;60(8):711- 4.

28. Bradshaw DJ, Marsh PD, Hodgson RJ, Visser JM. Effect of glucose and fluoride on competition and metabolism within dental bacterial communities and biofilms. Caries Res. 2002 Mar-Apr; 36(2):81- 6 .

29. ten Cate JM. Current concepts on the theories of the mechanism of action of fluoride. Acta Odontol Scand. 1999 Dec;57(6):325- 9 .

30. Cury JA, Tenuta LMA. How to maintain a cariostatic fluoride concentration in the oral environment. Adv Dent Res. 2008 Jul;20(1):13-6. 